\title{
Echo-free renal masses on ultrasound: the stethoscope as an adjunct to their diagnosis
}

\author{
R. Suarez* and A.H. Lynn $\dagger$ \\ Chelmsford and Essex Hospital, London Road, Chelmsford, Essex, CM2 0QH, UK.
}

\begin{abstract}
Summary: A patient with an intrarenal arteriovenous malformation is described. Ultrasound suggested this to be a renal cyst but auscultation revealed a loud bruit and, on the basis of this, arteriography rather than cyst puncture was carried out.
\end{abstract}

\section{Introduction}

Renal cysts are common and increase in frequency with age (Laucks \& McLachlan, 1951). In those patients who are found to have a renal mass on intravenous urography (IVU), ultrasound of the kidneys is the next investigation of choice (Pollack et al., 1974). Whether an apparently benign cyst should be punctured to confirm the diagnosis is open to debate, but the procedure is commonly carried out and is relatively free of complications (Lang, 1977).

However, not all echo-free renal masses are simple cysts and the differential diagnosis includes hydronephrosis, abscess, haematoma and vascular abnormalities (Green et al., 1976). We report a case where timely use of the stethoscope altered the radiological management of such a lesion.

\section{Case report}

A fit 53 year old female was referred with a history of painless haematuria. On examination she was found to be normotensive and the right kidney was palpable. An IVU (Figure 1) revealed a right parapelvic renal mass with distortion of the renal pelvis and lower calyces. Ultrasound showed an anechoic lesion in keeping with a cyst and the patient was admitted at a later date for cyst puncture. Auscultation of the abdomen on this occasion revealed a loud abdominal bruit maximal over the right kidney. In view of this, arteriography was performed rather than cyst punc-

R. Suarez, F.R.C.R.; A.H. Lynn, F.R.C.R.

Present addresses: ${ }^{*}$ Radiology Department, North Staffordshire Hospital Centre, Princes Road, Stoke-on-Trent, ST4 7LN. † Radiology Department, Hertford County Hospital, North Road, Hertford, SG14 ILP.

Correspondence: R. Suarez

Accepted: 21 June 1984

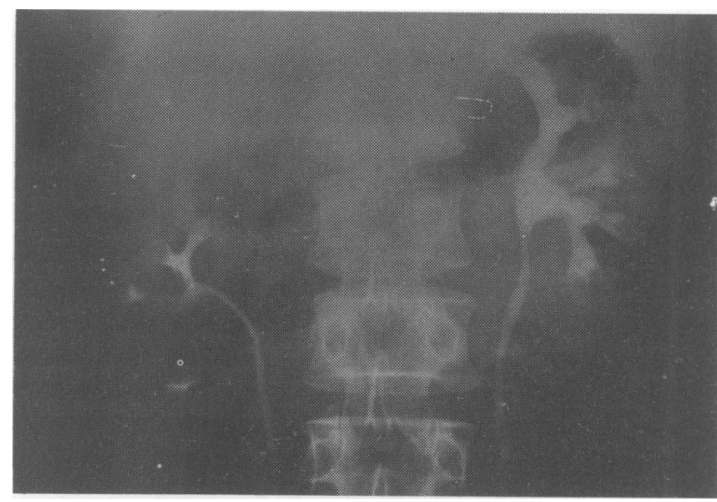

Figure 1 IVU film showing distortion of right pelvicalyceal system.

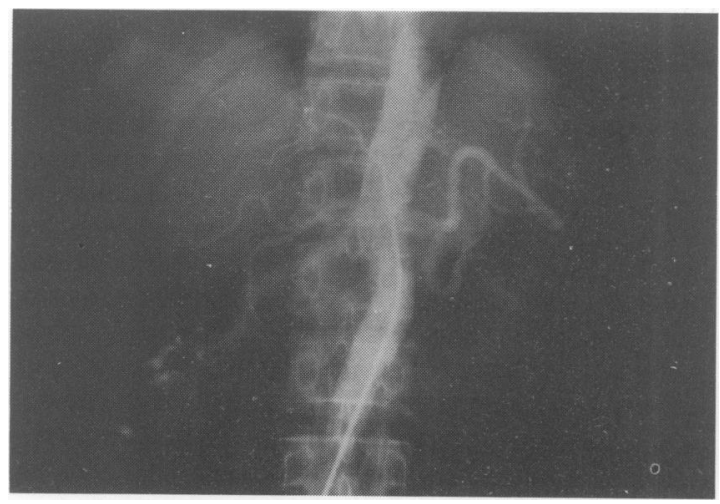

Figure 2 Aortogram showing vascular mass in right kidney.

ture (Figure 2). Selective catheterization of the right renal artery showed fibromuscular hyperplasia of the extra renal portion and a large intra-renal arterioven-

C The Fellowship of Postgraduate Medicine, 1985 
ous fistula. This was subsequently confirmed at histology following right nephrectomy. No other cause for the bleeding was identified and there was no further haematuria post-operatively.

\section{Discussion}

Intrarenal arteriovenous fistulae are uncommon and generally diagnosed by arteriography (Cho \& Stanley, 1978). More recently Subramanyam et al. (1983) have diagnosed these lesions prospectively with real-time ultrasound by showing a tubular anechoic lumen, possibly with thrombosis, and an enlarged main renal artery and vein confirming increased renal bloodflow.

Although not all renal arteriovenous fistulae produce an abdominal bruit, McAlhany et al. (1971), in their review of the subject, give the incidence of this sign as $74 \%$. We suggest that, particularly in parapelvic echo-free renal lesions, auscultation may prevent a surprise at cyst puncture (Hantman et al., 1982).

\section{Acknowledgements}

We wish to thank Mr B.W.T. Pender for his permission to report the case, Dr A.E. Hugh for his help with the manuscript and Mrs Tina Hill for secretarial assistance.

\section{References}

CHO, K.J. \& STANLEY, J.C. (1978). Non-neoplastic congenital and acquired renal arteriovenous malformations and fistulas. Radiology, 129, 333.

GREEN, W.M., KING, D.L. \& CASARELLA, W.J. (1976). A reappraisal of sonolucent renal masses. Radiology, 121, 163.

HANTMAN, S.S., BARIE, J.J., GLENDENING, T.B., EISENBERT, M.N. \& RAPOPORT, K.D. (1982). Giant renal artery aneurysm mimicking a simple cyst on ultrasound. Journal of Clinical Ultrasound, 10, 136.

LANG, E.K. (1977). Renal cyst puncture and aspiration: A survey of complications. American Journal of Roentgenology, 128, 723 .

LAUCKS, S.P. \& MCLACHLAN, M.S.F. (1981). Aging and simple cysts of the kidney. British Journal of Radiology, 54, 12.

MCALHANY, J.C., BLACK, H.C., HANBACK, L.D. \& YARBROUGH, D.R. (1971). Renal arteriovenous fistula as a cause of hypertension. American Journal of Surgery, 122, 117.

POLLACK, H.M., GOLDBERG, B.B., MORALES, J.O. \& BOGASH, M. (1974). A systematized approach to the differential diagnosis of renal masses. Radiology, 113, 653 . SUBRAMANYAM, B.R., LEFLEUR, R.S. \& BOSNIAK, N.A. (1983). Renal arteriovenous fistulas and aneurysm: sonographic findings. Radiology, 149, 261.

Figure 3 Subtraction film following selective right renal catherization, showing the fistula and fibromuscular hyperplasia of the extrarenal artery. 